\title{
Is Agomelatine Associated with Less Sedative-Hypnotic Usage in Patients with Major Depressive Disorder? A Nationwide, Population-Based Study
}

This article was published in the following Dove Press journal:

Neuropsychiatric Disease and Treatment

Shih-Chun Hsing, ${ }^{1,2}$ Yo-Ting Jin, ${ }^{3,4}$ NianSheng Tzeng, (iD ${ }^{5,6}$ ChiHsiang Chung, (ID) ${ }^{7-9}$ TienYu Chen, ${ }^{5,10,11}$ Hsin-An Chang, ${ }^{5,6}$ YuChen Kao, ${ }^{5,12}$ Wu-Chien Chien ${ }^{4,7-9}$

'Center for Healthcare Quality Management, Cheng Hsin General Hospital, Taipei, Taiwan; ${ }^{2}$ Department of Health Care Management, College of Health Technology, National Taipei University of Nursing and Heath Sciences, Taipei, Taiwan, Republic of China; ${ }^{3}$ Department of Nursing, Hsin Sheng Junior College of Medical Care and Management, Taoyuan, Taiwan; ${ }^{4}$ Graduate Institute of Life Sciences, National Defense Medical Center, Taipei, Taiwan; ${ }^{5}$ Department of Psychiatry, Tri-Service General Hospital, School of Medicine, National Defense Medical Center, Taipei, Taiwan; ${ }^{6}$ Student Counseling Center, National Defense Medical Center, Taipei, Taiwan;

${ }^{7}$ Department of Medical Research, Tri-Service General Hospital, National Defense Medical Center, Taipei, Taiwan; ${ }^{8}$ School of Public Health, National Defense Medical Center, Taipei, Taiwan; ${ }^{9}$ Taiwanese Injury Prevention and Safety Promotion Association, Taipei, Taiwan; ${ }^{10}$ Department of Psychiatry, TriService General Hospital, Keelung Branch, National Defense Medical Center, Taipei, Taiwan; "'Institute of Brain Science, National Yang-Ming University, Taipei, Taiwan; ${ }^{12}$ Department of Psychiatry, Tri-Service General Hospital, Song-Shan Branch, Nationa Defense Medical Center, Keelung, Taiwan

Correspondence: Nian-Sheng Tzeng Department of Psychiatry, School of Medicine, Tri-Service General Hospital, School of Medicine, National Defense Medical Center,

No. 325, Section 2, Cheng-Gung Road, Nei-Hu District, Taipei, Taiwan

Tel +886 2-879233 II, ext. 17484

Fax +886-2-8792722

Email pierrens@mail.ndmctsgh.edu.tw

Wu-Chien Chien

Department of Medical Research, Tri-Service General Hospital, National Defense Medical Center, 7II5R, No. 325, Section 2, Cheng-Gung Road, Nei-Hu District, Taipei, Taiwan

Tel +886 2-8792331I, ext. 19189

Fax +886 2-87927235

Email chienwu@ndmctsgh.edu.tw
Background: To examine the association between the usage of agomelatine in patients with major depressive disorder and the usage of sedative-hypnotics.

Methods: This population-based, cross-sectional study used Taiwan's National Health Insurance Research Database (NHIRD) between 2012 and 2015. The agomelatine-only group and matched control (1:3) with the usage of other antidepressants were enrolled. The association between the usage of the agomelatine and other antidepressants and the usage of sedative-hypnotics in the patients were also assessed.

Results: A total of 7961 subjects were enrolled comprising 1985 with the usage of agomelatine only, and 5976 with other antidepressants. In the present study, a total of 3322 subjects who used the sedative-hypnotics were recorded, with 811 (40.86\%) from the agomelatine-only group and $2511(42.02 \%)$ from the non-agomelatine group, which have used sedativehypnotics. After adjusting for covariates, the odds ratio (OR) of the usage of sedativehypnotics in the agomelatine only-group was 0.892 (95\% CI: $0.306-1.601, p=0.533)$, in comparison to the controls, and the relative risk (RR) of the usage of sedative-hypnotics in the agomelatine only-group was 0.910 (95\% CI: $0.312-1.633, p=0.520)$, in comparison to the controls. No matter as to whether the treatment duration was $<30$ days or $\geqq 30$ days of agomelatine treatment was not associated with the increased usage of the sedative-hypnotics. The OR or RR for usage of the sedative-hypnotics was associated with the Charlson Comorbidity Index (CCI) scores as 2,3 , and $\geqq 4$, and the medical care from the medical center and regional hospital.

Conclusion: Patients with the agomelatine-only group were not associated with the usage of sedative-hypnotics in comparison to the group using other antidepressants.

Keywords: agomelatine, insomnia, antidepressant, major depressive disorder, National Health Insurance Research Database

\section{Introduction}

Major depressive disorder (MDD) is one of the most common psychiatric disorders in adults, with significant burdens for the patients and the cost of treatment. ${ }^{1,2}$ Insomnia is one of the most common symptoms in MDD, and one study has reported that the prevalence rates for insomnia in MDD were $48.5 \%{ }^{3}$ Sedativehypnotics, such as benzodiazepines and Z-drugs, are widely used in patients with insomnia, and one report using Taiwan's National Health Insurance Research 
Database (NHIRD) estimated that $95.5 \%$ of patients with MDD have used the sedative-hypnotics. ${ }^{4}$ However, sedative-hypnotics have several disadvantages, such as the associations with the risk of falling-related injuries, ${ }^{5}$ suicide, ${ }^{6}$ dementia, ${ }^{7,8}$ and some respiratory or neurodegenerative diseases. $^{9-11}$ In addition, benzodiazepines are frequently used to treat insomnia; however, the side effects might include a withdrawal syndrome with rapid eye movement (REM) rebound. ${ }^{12}$

Antidepressants are widely used in the treatment of MDD. In addition, antidepressants have several effects on sleep: in short-term treatment, many activating antidepressant effects may disrupt sleep, while others with sedative properties rapidly improve sleep; however, all antidepressants should normalize sleep in the long-term treatment. ${ }^{13}$ Agomelatine, as a novel antidepressant for the treatment of MDD, could quickly improve the disturbed sleep-wake cycles, ${ }^{14}$ sleep efficiency, and correcting the circadian rhythm abnormalities, ${ }^{15}$ with a promising role for the treatment of sleep disorders associated with MDD. ${ }^{16}$ In addition, the melatonin (MT) receptor agonists are now appearing as the new promising treatment options for sleep and circadianrhythm-related disorders, such as agomelatine and ramelteon. ${ }^{17}$ Being the $\mathrm{MT}_{1}$ and $\mathrm{MT}_{2}$ receptors agonists, agomelatine is also an antagonist that affects the 5-hydroxytryptamine- $2 \mathrm{C}\left(5 \mathrm{HT}_{2 \mathrm{c}}\right)$ receptors. Since agomelatine acts on the suprachiasmatic nucleus, hippocampus, frontal cortex, and the striatum, it could lead to the improvement of both the sleep and mood. ${ }^{18,19}$ There are distinctive differential binding affinities to $\mathrm{MT}_{1}$ versus $\mathrm{MT}_{2}$ : Agomelatine binds to $\mathrm{MT}_{1}$ and $\mathrm{MT}_{2}$ receptors with approximately equal affinity and additional antagonist properties at the $5-\mathrm{HT}_{2 \mathrm{c}}$ receptors, and ramelteon exhibits a 10 -fold greater affinity for $\mathrm{MT}_{1}$ than $\mathrm{MT}_{2}{ }^{20,21}$ This might explain why there are differences in the effect of facilitations in sleep-onset between these two medications. However, problems of the sleep-wake cycle and circadian rhythm would be corrected by the usage of agomelatine. ${ }^{15,16}$ However, there has been little research done on the association between agomelatine and the usage of sedative-hypnotics. This study aimed to test the hypothesis as to whether being treated with agomelatine is less likely to be co-treated with sedative hypnotic agents.

\section{Materials and Methods}

\section{Data Sources}

The National Health Insurance (NHI) Program was launched in Taiwan in 1995, and as of June 2009, included contracts with $97 \%$ of the medical providers with approximately 23 million beneficiaries, or more than $99 \%$ of the entire population. $^{22}$ The NHIRD, which contains all the claims data of the beneficiaries, uses the International Classification of Diseases, 9th Revision, Clinical Modification (ICD-9-CM) codes to record the diagnoses, ${ }^{23}$ and were widely used in the medical studies with good diagnostic validity. ${ }^{24}$ The details of the program have been documented in previous studies. ${ }^{25-32}$ In the NHIRD, clinicians perform the coding based on the clinical diagnoses of the patients and according to the standards promulgated by the NHI Administration. Licensed medical records technicians would verify the coding before claiming the reimbursements. ${ }^{24}$ Furthermore, there is an audit mechanism to check the data of outpatient and emergency departments and hospitalization to ensure the accuracy of the data in the NHI Administration, in which the records were reviewed as 1 in 100 ambulatory care visits and 1 in 20 in-patient claims, so as to verify the accuracy of the diagnoses. ${ }^{33}$ Other efforts to ensure data validity including algorithms developed to identify targeted diagnosis and treatment by applying multiple criteria, and validation studies. A continuous and concerted action by the NHI and the researchers is required to address the issue. ${ }^{24}$ In Taiwan, agomelatine has been licensed since 2012. Therefore, a subset of the NHIRD, the Longitudinal Health Insurance Database (LHID) of a two million randomized sampled population between 2012 and 2015, was used to study the association between the agomelatine-only patients and the other antidepressant-controls, and the odds ratio (OR) and relative risk (RR) of the usage of sedative-hypnotics. In Taiwan, the dosage range of agomelatine is $25 \mathrm{mg}$ a day at bedtime and then up-titrated to a maximum dose of $50 \mathrm{mg}$ a day; however, an even higher dosage is not allowed. ${ }^{34}$ The present study used the NHIRD to identify the patients with the usage of agomelatine and other antidepressants.

\section{Ethical Approval}

This study was conducted according to the Code of Ethics of the World Medical Association (Declaration of Helsinki). This study was approved by the Institutional Review Board (IRB) of the Tri-Service General Hospital (TSGH). The TSGH IRB waived the need of individual consents since all the identification data were encrypted in the NHIRD (IRB No. B202005105 ).

\section{Study Design and Sampled Participants}

This study was of a population-based, cross-sectional design. Patients with MDD (ICD-9-CM codes: 296.2x, 
296.3x), who had used different classes of antidepressants (Table S1), were enrolled from the LHID between January 1, 2012, and December 31, 2015. The group entry date was defined as the first prescription date of agomelatine or other antidepressants during the study period. The cases and the control subjects were selected 1:3 by the estimated propensity score matched by sex, age, and index-year. The usage of the sedative-hypnotics was recorded in this study. The study outcome was the OR for the usage of the sedative-hypnotics.

\section{Covariates}

The covariates included sex, age, marital status, educational years $(<12$ years and $\geq 12$ years), monthly insurance premiums (in New Taiwan Dollars [NT\$]; $<18,000$, $18,000-34,999, \geq 35,000)$, geographical locations of residence (north, center, south, and east of Taiwan), urbanization levels of residence (levels 1 to 4 ), seasons of help-seeking, and levels of medical care. We used the Charlson Comorbidity Index, which categorizes the comorbidities using the ICD-9-CM codes, scores each comorbidity category, and combines all the scores to calculate a single comorbidity score, with the scores as CCI, $0,1,2,3, \geq 4$. A score of zero indicated that no comorbidities were found, and higher scores indicated the higher comorbidity burdens. ${ }^{35-37}$ Figure 1 presents a detailed flowchart regarding the subject selection and the study design.

\section{Statistical Analysis}

The chi-square test was adapted to examine the differences in the distributions between the usage of antidepressants and the OR and RR of the usage of sedative-hypnotics. Multivariable logistic regression was employed to calculate the impact of demographic characteristics, types, and durations of antidepressants on the OR of the usage of sedative-hypnotics. The level of significance (a two-tailed $p$ value) was maintained at $<0.05$ for all statistical analyses. The statistical analyses were performed using the software SPSS 22.0.

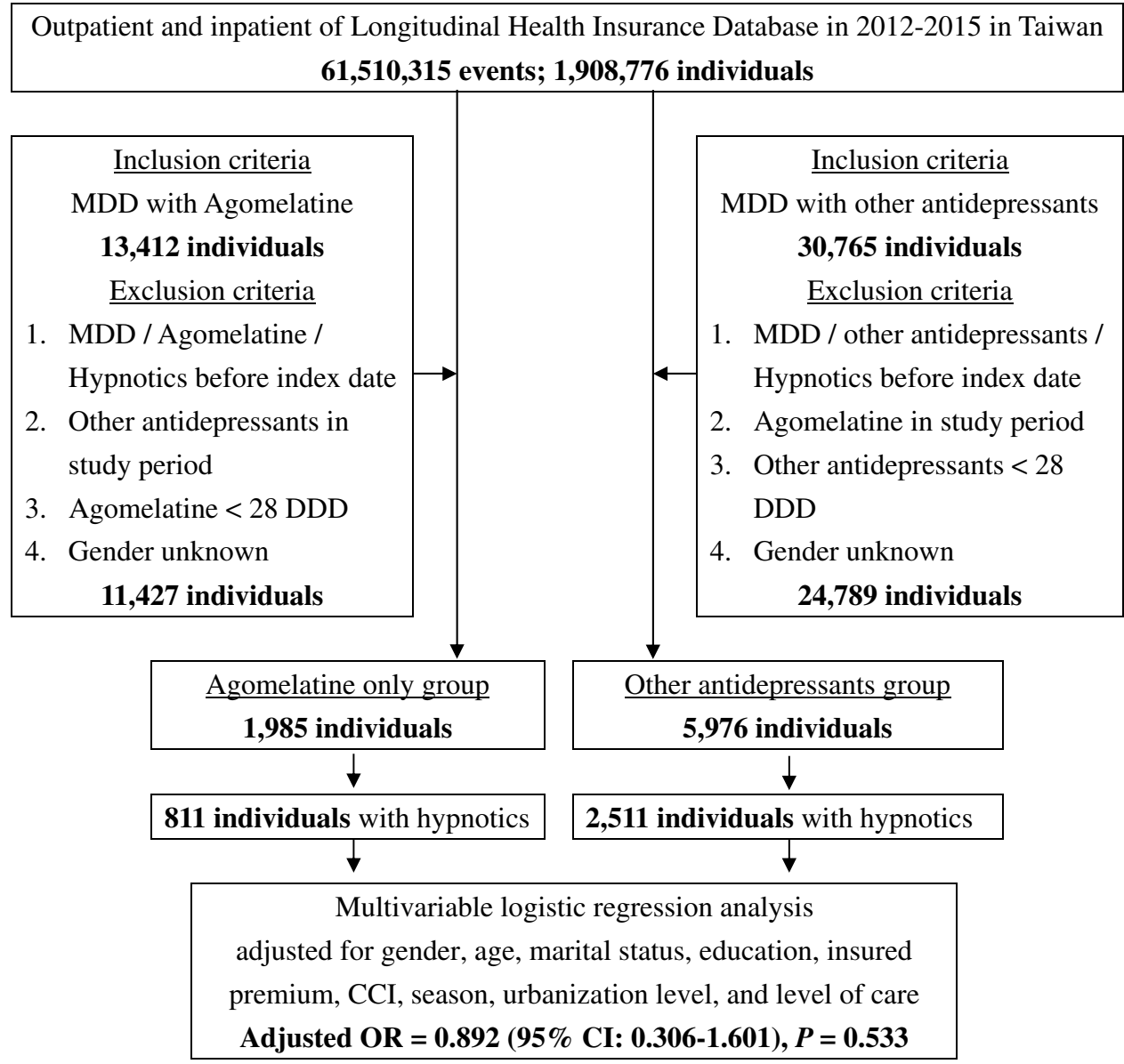

Figure I The flowchart of study sample selection (cross-section study). 


\section{Results}

\section{Sample Characteristics}

A total of 7961 subjects were enrolled comprising 1985 with the usage of agomelatine only and 5976 with other antidepressants. Table 1 shows the sex, age, marital status, monthly insurance premiums, education, CCI scores, seasons of the medical help-seeking, urbanization, locations of residence, for the agomelatine only-patients, and the other antidepressant-controls. When compared to the other antidepressants-controls, the agomelatine onlypatients tended to have the lower CCI scores. The agomelatine only-patients tended to have higher rates of living in the middle and south of Taiwan and seeking help in the medical centers than the control groups.

\section{Odds Ratio Analysis of the Usage of Sedative-Hypnotics in Agomelatine Only-Patients}

Table 2 shows the multivariable logistic regression analysis of the factors associated with the risk of the usage of sedative-hypnotics. The crude OR was 0.986 (95\% CI: $0.423-1.775, p=0.452$ ), after adjusting for the covariates, the adjusted OR was 0.892 (95\% CI: 0.306-1.601, $p=$ 0.533). There were increased ORs for the usage of the sedative-hypnotics that were associated with the CCI scores as 2,3 , and $\geqq 4$, and the medical care from the medical center and regional hospital.

\section{Relative Risk Analysis of the Usage of Sedative-Hypnotics in Agomelatine Only-Patients}

Table 3 shows the relative risk analysis of the factors associated with the risk of the usage of sedative-hypnotics. The crude RR was 0.996 ( $95 \%$ CI: $0.425-0.755, p=0.452$ ), after adjusting for the covariates, the adjusted RR was 0.910 (95\% CI: $0.312-1.633, p=0.520$ ). There were increased RRs for the usage of the sedative-hypnotics that were associated with the CCI scores as 2,3 , and $\geqq 4$, and the medical care from the medical center and regional hospital.

\section{Odds Ratio and Relative Risk Analysis of the Usage of Sedative-Hypnotics in Agomelatine Only-Patients}

The association between the agomelatine only-group and other antidepressants was insignificant for the usage of
Table I Characteristics of Two Groups in the Present Study

\begin{tabular}{|c|c|c|c|c|c|}
\hline \multirow{2}{*}{$\begin{array}{l}\text { Antidepressants } \\
\text { Variables }\end{array}$} & \multicolumn{2}{|c|}{$\begin{array}{l}\text { Agomelatine } \\
\text { Only }\end{array}$} & \multicolumn{2}{|c|}{$\begin{array}{l}\text { Other } \\
\text { Antidepressants }\end{array}$} & \multirow[t]{2}{*}{$\mathbf{P}$} \\
\hline & $\mathbf{n}$ & $\%$ & $\mathbf{n}$ & $\%$ & \\
\hline Total & 1985 & 24.93 & 5976 & 75.07 & \\
\hline Hypnotics & & & & & 0.363 \\
\hline Without & 1174 & 59.14 & 3465 & 57.98 & \\
\hline With & 811 & 40.86 & 2511 & 42.02 & \\
\hline Sex & & & & & 0.663 \\
\hline Male & 1016 & 51.18 & 3025 & 50.62 & \\
\hline Female & 969 & 48.82 & 2951 & 49.38 & \\
\hline Age (years) & \multicolumn{2}{|c|}{$45.97 \pm 19.76$} & \multicolumn{2}{|c|}{$40.97 \pm 18.32$} & $<0.001$ \\
\hline Marital status & & & & & 0.828 \\
\hline Without & 961 & 48.41 & 2910 & 48.69 & \\
\hline With & 1024 & 51.59 & 3066 & 51.31 & \\
\hline Education (years) & & & & & 0.871 \\
\hline$<12$ & 988 & 49.77 & 2987 & 49.98 & \\
\hline$\geqq 12$ & 997 & 50.23 & 2989 & 50.02 & \\
\hline $\begin{array}{l}\text { Insured premium } \\
\text { (NT\$) }\end{array}$ & & & & & 0.782 \\
\hline$<18,000$ & 1778 & 89.57 & 5331 & 89.21 & \\
\hline $18,000-34,999$ & 164 & 8.26 & 522 & 8.73 & \\
\hline$\geqq 35,000$ & 43 & 2.17 & 123 & 2.06 & \\
\hline $\mathrm{CCl}$ & & & & & $<0.001$ \\
\hline 0 & 798 & 40.20 & 1882 & 31.49 & \\
\hline 1 & 531 & 26.75 & 1495 & 25.02 & \\
\hline 2 & 309 & 15.57 & 1204 & 20.15 & \\
\hline 3 & 297 & 14.96 & 1229 & 20.57 & \\
\hline$\geqq 4$ & 50 & 2.52 & 166 & 2.78 & \\
\hline Season & & & & & 0.523 \\
\hline Spring (March-May) & 488 & 24.58 & 1426 & 23.86 & \\
\hline Summer (June-- & 520 & 26.20 & 1668 & 27.91 & \\
\hline August) & & & & & \\
\hline Autumn (September- & 511 & 25.74 & 1516 & 25.37 & \\
\hline November) & & & & & \\
\hline $\begin{array}{l}\text { Winter (December- } \\
\text { February) }\end{array}$ & 466 & 23.48 & 1366 & 22.86 & \\
\hline Location & & & & & $<0.001$ \\
\hline Northern Taiwan & 735 & 37.03 & 2312 & 38.69 & \\
\hline Middle Taiwan & 468 & 23.58 & 1213 & 20.30 & \\
\hline Southern Taiwan & 493 & 24.84 & 1264 & 21.15 & \\
\hline Eastern Taiwan & 280 & 14.11 & 1100 & 18.41 & \\
\hline Outlying islands & 9 & 0.45 & 87 & 1.46 & \\
\hline Urbanization level & & & & & 0.235 \\
\hline I (The highest) & 701 & 35.31 & 2221 & 37.17 & \\
\hline 2 & 812 & 40.91 & 2420 & 40.50 & \\
\hline 3 & 211 & 10.63 & 555 & 9.29 & \\
\hline 4 (The lowest) & 261 & 13.15 & 780 & 13.05 & \\
\hline
\end{tabular}

(Continued) 
Table I (Continued).

\begin{tabular}{|l|l|l|l|l|l|}
\hline Antidepressants & \multicolumn{2}{|l|}{$\begin{array}{l}\text { Agomelatine } \\
\text { Only }\end{array}$} & \multicolumn{2}{l|}{$\begin{array}{l}\text { Other } \\
\text { Antidepressants }\end{array}$} & \\
\hline Variables & $\mathbf{n}$ & $\%$ & $\mathbf{n}$ & $\%$ & \\
\hline Level of care & & & & & \multirow{2}{*}{$<0.001$} \\
Medical center & 768 & 38.69 & 1813 & 30.34 & \\
Regional hospital & 811 & 40.86 & 2876 & 48.13 & \\
Local hospital & 406 & 20.45 & 1287 & 21.54 & \\
\hline
\end{tabular}

Note: P: Chi-square/Fisher exact test on category variables and t-test on continue variables.

Abbreviation: NT\$, New Taiwan Dollars.

different treatment durations. No matter that the treatment durations were $<30$ days or $\geqq 30$ days of agomelatine treatment in both the OR analysis (Table 4) and the RR analysis (Table 5).

\section{Discussion}

The present study has found that being treated with agomelatine was not associated with a lower OR and RR as being co-treated with sedative hypnotic agents, even though previous studies have shown that agomelatine was beneficial to several sleep problems. Agomelatine could enhance their sleep cycle ${ }^{38,39}$ by resynchronization of the circadian rhythm. ${ }^{13,40}$ In addition, agomelatine is the only antidepressant with a lower likelihood of inducing insomnia. ${ }^{41}$ Furthermore, agomelatine might be a valuable addition to the pharmacological repertoire for the treatment of alcohol dependence-associated insomnia. ${ }^{42}$ To the best of our knowledge, this is the first nationwide, population-based study on the topic of the usage of sedativehypnotics in the patients using agomelatine.

In the present study, the increased OR or RR for usage of the sedative-hypnotics was associated with the CCI scores as 2,3 , and $\geqq 4$, and the medical care from the medical center and regional hospital. This might support the previous findings that sleep disorders are prevalent in patients with more medical comorbidities ${ }^{43,44}$ or even need a higher medical attention. ${ }^{45,46}$ In addition, there appeared to be more middle CCI scores as 2,3 , and $\geqq 4$ in the other

Table 2 Factors of Sedative-Hypnotics by Using Multivariable Logistic Regression

\begin{tabular}{|c|c|c|c|c|c|c|c|c|}
\hline $\begin{array}{l}\text { Variables } \\
\text { Antidepressants }\end{array}$ & Crude OR & $95 \% \mathrm{Cl}$ & $95 \% \mathrm{Cl}$ & $\boldsymbol{P}$ & Adjusted OR & $95 \% \mathrm{Cl}$ & $95 \% \mathrm{Cl}$ & $\mathbf{P}$ \\
\hline Agomelatine only & 0.986 & 0.423 & 1.775 & 0.452 & 0.892 & 0.306 & 1.601 & 0.533 \\
\hline Age (years) & 1.791 & 1.226 & 2.006 & 0.001 & 1.642 & 1.125 & 1.864 & 0.003 \\
\hline $\mathrm{CCl}=2$ (reference: $\mathrm{CCl}=0$ ) & 1.240 & 0.986 & 1.302 & 0.062 & 1.286 & 1.003 & 1.482 & 0.048 \\
\hline $\mathrm{CCl}=3$ (reference: $\mathrm{CCl}=0$ ) & 1.335 & 1.153 & 1.565 & $<0.001$ & 1.465 & 1.201 & 1.798 & $<0.001$ \\
\hline $\mathrm{CCl} \geqq 4$ (reference: $\mathrm{CCl}=0$ ) & 1.298 & 1.098 & 1.443 & 0.004 & 1.333 & 1.145 & 1.665 & $<0.001$ \\
\hline Autumn (reference: spring) & 1.997 & 1.232 & 3.375 & $<0.001$ & 1.842 & 1.124 & 2.977 & 0.001 \\
\hline Level I (reference: level 4) & 2.501 & 1.297 & 5.340 & $<0.001$ & 1.642 & 1.065 & 4.435 & 0.027 \\
\hline Medical center (reference: local hospital) & 3.011 & 2.401 & 4.020 & $<0.001$ & 2.660 & 2.343 & 2.999 & $<0.001$ \\
\hline Regional hospital (reference: local hospital) & 2.066 & 1.564 & 2.868 & $<0.001$ & 1.765 & $|| 3 \mid$. & 1.986 & $<0.001$ \\
\hline
\end{tabular}

Abbreviations: OR, odds ratio; $\mathrm{Cl}$, confidence interval; Adjusted $\mathrm{OR}$, adjusted variables listed in the table; $\mathrm{CCl}$, Charlson Comorbidity Index.

Table 3 Factors of Sedative-Hypnotics by Using Relative Risk Analysis

\begin{tabular}{|c|c|c|c|c|c|c|c|c|}
\hline $\begin{array}{l}\text { Variables } \\
\text { Antidepressants }\end{array}$ & Crude RR & $95 \% \mathrm{Cl}$ & $95 \% \mathrm{Cl}$ & $\boldsymbol{P}$ & Adjusted RR & $95 \% \mathrm{Cl}$ & $95 \% \mathrm{Cl}$ & $P$ \\
\hline Agomelatine only & 0.996 & 0.425 & 0.755 & 0.443 & 0.910 & 0.312 & 1.633 & 0.520 \\
\hline Age (years) & 1.827 & 1.240 & 2.483 & 0.001 & 1.675 & 1.148 & 1.901 & 0.003 \\
\hline $\mathrm{CCl}=2$ (reference: $\mathrm{CCl}=0$ ) & 1.265 & 1.025 & 1.624 & 0.044 & 1.312 & 1.023 & 1.512 & 0.047 \\
\hline $\mathrm{CCl}=3$ (reference: $\mathrm{CCl}=0$ ) & 1.462 & 1.370 & 2.457 & $<0.001$ & 1.494 & 1.225 & 1.834 & $<0.001$ \\
\hline $\mathrm{CCl} \geqq 4$ (reference: $\mathrm{CCl}=0$ ) & 1.324 & 1.189 & 2.098 & 0.004 & 1.360 & 1.168 & 1.698 & $<0.001$ \\
\hline Autumn (reference: spring) & 2.037 & 1.452 & 4.257 & $<0.001$ & 1.879 & 1.147 & 3.037 & 0.001 \\
\hline Urbanization Level I (reference: level 4) & 2.551 & 1.309 & 17.669 & $<0.001$ & 1.675 & 1.086 & 4.524 & 0.026 \\
\hline Medical center (reference: local hospital) & 3.071 & 2.375 & 5.904 & $<0.001$ & 2.713 & 2.390 & 3.059 & $<0.001$ \\
\hline Regional hospital (reference: local hospital) & 2.107 & 1.986 & 4.256 & $<0.001$ & 1.800 & 1.154 & 2.026 & $<0.001$ \\
\hline
\end{tabular}

Abbreviations: RR, relative risk; Cl, confidence interval; Adjusted RR, adjusted variables listed in the Table I; CCl, Charlson Comorbidity Index. 
Table 4 Comparing the Odd Ratios of Hypnotics Between Agomelatine Only and Other Antidepressants by Using Multivariable Logistic Regression

\begin{tabular}{|c|c|c|c|c|c|c|c|c|}
\hline \multirow[t]{2}{*}{ DDD } & \multirow[t]{2}{*}{ Antidepressants Subgroup } & \multirow{2}{*}{$\begin{array}{l}\text { Populations } \\
\mathbf{n}\end{array}$} & \multicolumn{2}{|c|}{ Hypnotics } & \multicolumn{4}{|c|}{ Agomelatine Only vs Other Antidepressants (Reference) } \\
\hline & & & $\mathbf{n}$ & $\%$ & Adjusted OR & $95 \% \mathrm{Cl}$ & $95 \% \mathrm{Cl}$ & $P$ \\
\hline \multirow[t]{7}{*}{ Overall } & Agomelatine only & 1985 & 811 & 40.86 & & & & \\
\hline & Other Antidepressants, Overall & 5976 & 2511 & 42.02 & 0.892 & 0.306 & 1.601 & 0.533 \\
\hline & TCA & 2012 & 798 & 39.66 & 0.841 & 0.288 & 1.365 & 0.503 \\
\hline & SSRI & 2352 & 896 & 38.10 & 0.802 & 0.275 & 1.251 & 0.484 \\
\hline & SNRI & 2111 & 765 & 36.24 & 0.766 & 0.263 & 1.186 & 0.462 \\
\hline & NDRI & 1986 & 872 & 43.91 & 0.935 & 0.321 & 1.456 & 0.550 \\
\hline & RIMA & 2028 & 803 & 39.60 & 0.841 & 0.289 & 1.311 & 0.511 \\
\hline \multirow[t]{7}{*}{ I-29 } & Agomelatine only & 862 & 366 & 42.46 & & & & \\
\hline & Other Antidepressants, Overall & 2233 & 901 & 40.35 & 0.824 & 0.284 & 1.289 & 0.493 \\
\hline & TCA & 990 & 355 & 35.86 & 0.732 & 0.249 & I.I44 & 0.432 \\
\hline & SSRI & 1024 & 429 & 41.89 & 0.856 & 0.293 & 1.335 & 0.515 \\
\hline & SNRI & 986 & 376 & 38.13 & 0.777 & 0.265 & 1.215 & 0.464 \\
\hline & NDRI & 971 & 425 & 43.77 & 0.893 & 0.303 & 1.383 & 0.533 \\
\hline & RIMA & 1011 & 390 & 38.58 & 0.787 & $0.27 I$ & 1.226 & 0.472 \\
\hline \multirow[t]{7}{*}{$\geqq 30$} & Agomelatine only & 1123 & 445 & 39.63 & & & & \\
\hline & Other Antidepressants, Overall & 3743 & 1610 & 43.01 & 0.940 & 0.322 & 1.462 & 0.563 \\
\hline & TCA & 1022 & 443 & 43.35 & 0.950 & 0.321 & 1.489 & 0.572 \\
\hline & SSRI & 1328 & 467 & 35.17 & 0.771 & 0.262 & 1.211 & 0.462 \\
\hline & SNRI & 1125 & 389 & 34.58 & 0.753 & 0.258 & 1.186 & 0.451 \\
\hline & NDRI & 1015 & 447 & 44.04 & 0.962 & 0.333 & 1.503 & 0.578 \\
\hline & RIMA & 1017 & 413 & 40.61 & 0.888 & 0.301 & 1.397 & 0.530 \\
\hline
\end{tabular}

Abbreviations: DDD, days of drugs used; RR, relative risk; Cl, confidence interval; Adjusted RR, adjusted variables listed in Table 2; TCA, tricyclic antidepressant; SSRI, selective serotonin reuptake inhibitor; SNRI, serotonin norepinephrine reuptake inhibitor; NDRI, norepinephrine dopamine reuptake inhibitor; RIMA, reversible monoamine oxidase inhibitor.

antidepressant group. There is no study, as yet, for the agomelatine treatment for depression in people with physical comorbidities. The reason we speculate is that physicians tended to prescribe familiar antidepressants, which were frequently used for patients with both physical illness and depression, ${ }^{47,48}$ instead of agomelatine, which has been licensed since 2012 in Taiwan.

High pressure of life accompanying living in the higher urbanized area could be related to the association between the agomelatine group in the higher urbanized area and the increased OR and RR of the usage of the sedativehypnotics. ${ }^{49,50}$ The agomelatine group who sought medical help in the autumn was associated with a higher risk of using the sedative-hypnotics, and this might well be related to the fact that sleep disturbance could be associated with the significant shortening of exposure to sunlight in this season. ${ }^{51}$ In addition, antidepressant treatment-emergent insomnia is a critical issue in the treatment of depression. ${ }^{13,40}$ Thus, the study aims to address a topic of high public health importance, although the association is not significant. A longer follow-up, cohort study would be necessary to clarify as to whether the correction of the sleep-wake cycle and circadian rhythm by agomelatine would be effective in reducing the usage of the sedative-hypnotics for the depressive patients who use agomelatine.

Furthermore, since several studies have reported that agomelatine could be a novel therapeutic approach for disorders other than MDD, such as irritable bowel syndrome $^{52}$ and epilepsy, ${ }^{53}$ agomelatine could be suitable for patients with prominent sleep difficulties, or insomnia, for patients with these comorbidities. However, patients using agomelatine require regular liver function checks for the possible hepatotoxic effects. ${ }^{52,54}$ In addition, several other side effects, such as dizziness, ${ }^{55}$ also require the clinicians' attention and management.

\section{Strengths of This Study}

This study has several strengths. First, the present study has been examined from Taiwan's NHIRD, which is a valuable resource to cover a nationwide population, to 
Table 5 Comparing the Relative Risk of Hypnotics Between Agomelatine Only and Other Antidepressants

\begin{tabular}{|c|c|c|c|c|c|c|c|c|}
\hline \multirow[t]{2}{*}{ DDD } & \multirow[t]{2}{*}{ Antidepressants Subgroup } & \multirow{2}{*}{$\begin{array}{l}\text { Populations } \\
\mathrm{n}\end{array}$} & \multicolumn{2}{|c|}{ Hypnotics } & \multicolumn{4}{|c|}{ Agomelatine Only vs Other Antidepressants (Reference) } \\
\hline & & & $\mathbf{n}$ & $\%$ & Adjusted RR & $95 \% \mathrm{Cl}$ & $95 \% \mathrm{Cl}$ & $\mathbf{P}$ \\
\hline \multirow[t]{7}{*}{ Overall } & Agomelatine only & 1985 & 811 & 40.86 & & & & \\
\hline & Other Antidepressants, Overall & 5976 & 2511 & 42.02 & 0.910 & 0.312 & 1.633 & 0.523 \\
\hline & TCA & 2012 & 798 & 39.66 & 0.857 & 0.294 & 1.394 & 0.493 \\
\hline & SSRI & 2352 & 896 & 38.10 & 0.816 & 0.281 & 1.276 & 0.474 \\
\hline & SNRI & 2111 & 765 & 36.24 & 0.782 & 0.262 & 1.212 & 0.453 \\
\hline & NDRI & 1986 & 872 & 43.91 & 0.953 & 0.326 & 1.489 & 0.539 \\
\hline & RIMA & 2028 & 803 & 39.60 & 0.857 & 0.293 & 1.335 & 0.501 \\
\hline \multirow[t]{7}{*}{$1-29$} & Agomelatine only & 862 & 366 & 42.46 & & & & \\
\hline & Other Antidepressants, Overall & 2233 & 901 & 40.35 & 0.840 & 0.289 & 1.319 & 0.483 \\
\hline & TCA & 990 & 355 & 35.86 & 0.747 & 0.254 & 1.167 & 0.424 \\
\hline & SSRI & 1024 & 429 & 41.89 & 0.872 & 0.297 & 1.365 & 0.505 \\
\hline & SNRI & 986 & 376 & 38.13 & 0.793 & 0.264 & 1.239 & 0.455 \\
\hline & NDRI & 971 & 425 & 43.77 & 0.913 & 0.308 & 1.413 & 0.523 \\
\hline & RIMA & 1011 & 390 & 38.58 & 0.801 & 0.276 & 1.250 & 0.463 \\
\hline \multirow[t]{7}{*}{$\geqq 30$} & Agomelatine only & 1123 & 445 & 39.63 & & & & \\
\hline & Other Antidepressants, Overall & 3743 & 1610 & 43.01 & 0.959 & 0.328 & 1.492 & 0.552 \\
\hline & TCA & 1022 & 443 & 43.35 & 0.963 & 0.321 & 1.518 & 0.561 \\
\hline & SSRI & 1328 & 467 & 35.17 & 0.788 & 0.265 & 1.235 & 0.453 \\
\hline & SNRI & 1125 & 389 & 34.58 & 0.764 & 0.263 & 1.213 & 0.442 \\
\hline & NDRI & 1015 & 447 & 44.04 & 0.972 & 0.341 & 1.530 & 0.567 \\
\hline & RIMA & 1017 & 413 & 40.61 & 0.915 & 0.308 & 1.425 & 0.520 \\
\hline
\end{tabular}

Abbreviations: DDD, days of drugs used; RR, relative risk; Cl, confidence interval; Adjusted RR, adjusted variables listed in Table 2; TCA, tricyclic antidepressant; SSRI, selective serotonin reuptake inhibitor; SNRI, serotonin norepinephrine reuptake inhibitor; NDRI, norepinephrine dopamine reuptake inhibitor; RIMA, reversible monoamine oxidase inhibitor.

address this issue. Second, several previous studies have demonstrated the accuracy and validity of several diagnoses of neuro-psychiatric disorders in the NHIRD, such as Tourette syndrome, ${ }^{56}$ stroke, ${ }^{57-60}$ and sleep apnea. ${ }^{61}$ Furthermore, studies have also depicted the concordance between Taiwan's National Health Survey and the NHIRD on a variety of diagnoses, ${ }^{62}$ medication usage, ${ }^{62}$ and health system utilizations. ${ }^{62,63}$

\section{Limitations}

This study has several limitations. First, the records of the usage of agomelatine, other antidepressants, and the sedative-hypnotics were recorded in the NHIRD. However, the usage of these medications was assessed based on the prescription records, but the medication compliance and the rate of refills were unknown. Second, diagnoses of the MDD were identified by the ICD-9-CM codes, and the coding errors could be a problem of the NHIRD; therefore, misclassification bias might be an issue. However, large data sets could potentially overcome this problem. ${ }^{24}$ In addition, as aforementioned, the verification of in- hospital licensed medical record technician and audit from the NHI Administration would have ensured the accuracy of the data coding process. Third, several important unmeasured confounding factors may have affected the results. For example, the lifestyle of the patients taking antidepressants such as drinking coffee or napping routines was not able to be assessed by the NHIRD. Fourth, similar to previous studies using the NHIRD, the severity, laboratory parameters, genetic, psychosocial, and environmental factors, were not included in the database. Fifth, in this study, the enrolled MDD subjects, with the treatment of agomelatine and other antidepressants, were not stratified by multiple disorders in this database. This is a limitation since anxiety and pain disorders might influence the prevalence of sleep disturbances and the usage of sedative-hypnotic medications in these MDD patients. Sixth, several clinicians would prescribe low dose antidepressants as a sedative-hypnotic medication. However, in this study, the usage of the antidepressants as sedativehypnotic medications was not analyzed. Seventh, we used 30 days as a cut-off for comparison since the acute phase 
treatment is 30 days of treatment duration. Nonetheless, agomelatine had slightly higher response rates as 1.08 (95\% CI: 1.02-1.15) when compared to the selective serotonin reuptake inhibitors and serotonin-norepinephrine reuptake inhibitors in the acute phase, ${ }^{64}$ and this could be a limitation. Finally, further verification of the generalizability of our results to other countries is therefore needed.

\section{Conclusion}

Patients with the agomelatine-only group were not associated with more usage of the sedative-hypnotics than that in the other antidepressant-group. The risk of the usage of sedative-hypnotics was associated with more comorbidities, higher medical care levels, the autumn season of the medical help-seeking, and the subjects living in urban areas. A longer follow-up study would be necessary to clarify as to whether the agomelatine usage is related to the decreased amount of usage of the sedative-hypnotics.

\section{Data Sharing Statement}

Data are available from the National Health Insurance Research Database (NHIRD) published by the Taiwan National Health Insurance (NHI) Administration. Due to legal restrictions imposed by the government of Taiwan in relation to the "Personal Information Protection Act", data cannot be made publicly available. Requests for data can be sent as a formal proposal to the NHIRD (http://www. mohw.gov.tw/cht/DOS/DM1.aspx?f list no=812).

\section{Acknowledgments}

This work was supported by the Medical Affairs Bureau, the Ministry of Defense of Taiwan (MAB-107-084), and the Tri-Service General Hospital Research Foundation (TSGH-C108-151, and TSGH-B-109-010). These funding agencies did not influence the study design, data collection and analysis, decision to publish, or preparation of the manuscript. We also appreciate Taiwan's Health and Welfare Data Science Center and the Ministry of Health and Welfare (HWDC, MOHW) for providing the National Health Research Database.

\section{Author Contributions}

All authors made substantial contributions to conception and design, acquisition of data, or analysis and interpretation of data; took part in drafting the article or revising it critically for important intellectual content; gave final approval of the version to be published; and agreed to be accountable for all aspects of the work. In addition, C-H Chung and W-C Chien conducted the data extraction process and the data were cross-checked by S-C Hsing and N-S Tzeng.

\section{Disclosure}

The authors declare that the research was conducted in the absence of any commercial, financial, and non-financial relationships that could be construed as a potential conflict of interest.

\section{References}

1. Cipriani A, Furukawa TA, Salanti G, et al. Comparative efficacy and acceptability of 21 antidepressant drugs for the acute treatment of adults with major depressive disorder: a systematic review and network meta-analysis. Lancet. 2018;391(10128):1357-1366. doi:10. 1016/S0140-6736(17)32802-7

2. Gauthier G, Guerin A, Zhdanava M, et al. Treatment patterns, healthcare resource utilization, and costs following first-line antidepressant treatment in major depressive disorder: a retrospective US claims database analysis. BMC Psychiatry. 2017;17(1):222. doi:10.1186/ s12888-017-1385-0

3. Geoffroy PA, Hoertel N, Etain B, et al. Insomnia and hypersomnia in major depressive episode: prevalence, sociodemographic characteristics and psychiatric comorbidity in a population-based study. $J$ Affect Disord. 2018;226:132-141. doi:10.1016/j.jad.2017.09.032

4. Chien IC, Bih SH, Lin CH, et al. Correlates and psychiatric disorders associated with psychotropic drug use in Taiwan. Soc Psychiatry Psychiatr Epidemiol. 2011;46(1):77-84. doi:10.1007/s00127-0090169-3

5. Yu NW, Chen PJ, Tsai HJ, et al. Association of benzodiazepine and Z-drug use with the risk of hospitalisation for fall-related injuries among older people: a nationwide nested case-control study in Taiwan. BMC Geriatr. 2017;17(1):140. doi:10.1186/s12877-0170530-4

6. Sun Y, Lin CC, Lu CJ, Hsu CY, Kao CH. Association between zolpidem and suicide: a nationwide population-based case-control study. Mayo Clin Proc. 2016;91(3):308-315. doi:10.1016/j.mayocp.2015.10.022

7. Cheng HT, Lin FJ, Erickson SR, Hong JL, Wu CH. The association between the use of zolpidem and the risk of alzheimer's disease among older people. J Am Geriatr Soc. 2017;65(11):2488-2495. doi:10.1111/jgs. 15018

8. Shih HI, Lin CC, Tu YF, et al. An increased risk of reversible dementia may occur after zolpidem derivative use in the elderly population: a population-based case-control study. Medicine. 2015;94(17):e809. doi:10.1097/MD.0000000000000809

9. Chen SJ, Yeh CM, Chao TF, et al. The use of benzodiazepine receptor agonists and risk of respiratory failure in patients with chronic obstructive pulmonary disease: a nationwide population-based case-control study. Sleep. 2015;38(7):1045-1050. doi:10.5665/sleep.4808

10. Kok VC, Horng JT, Hung GD, et al. Risk of autoimmune disease in adults with chronic insomnia requiring sleep-inducing pills: a population-based longitudinal study. J Gen Intern Med. 2016;31 (9):1019-1026. doi:10.1007/s11606-016-3717-z

11. Yang YW, Hsieh TF, Yu CH, Huang YS, Lee CC, Tsai TH. Zolpidem and the risk of Parkinson's disease: a nationwide population-based study. J Psychiatr Res. 2014;58:84-88. doi:10.1016/j.jpsychires. 2014.07.003

12. Pagel JF, Parnes BL. Medications for the treatment of sleep disorders: an overview. Prim Care Companion J Clin Psychiatry. 2001;3(3):118-125. doi:10.4088/PCC.v03n0303 
13. Wichniak A, Wierzbicka A, Walecka M, Jernajczyk W. Effects of antidepressants on sleep. Curr Psychiatry Rep. 2017;19(9):63. doi:10.1007/s11920-017-0816-4

14. Quera-Salva MA, Lemoine P, Guilleminault C. Impact of the novel antidepressant agomelatine on disturbed sleep-wake cycles in depressed patients. Hum Psychopharmacol. 2010;25(3):222-229.

15. Pandi-Perumal SR, Moscovitch A, Srinivasan V, Spence DW, Cardinali DP, Brown GM. Bidirectional communication between sleep and circadian rhythms and its implications for depression: lessons from agomelatine. Prog Neurobiol. 2009;88(4):264-271. doi:10.1016/j.pneurobio.2009.04.007

16. Srinivasan V, Zakaria R, Othaman Z, Brzezinski A, Prasad A, Brown GM. Melatonergic drugs for therapeutic use in insomnia and sleep disturbances of mood disorders. CNS Neurol Disord Drug Targets. 2012;11(2):180-189. doi:10.2174/187152712800269740

17. Spadoni G, Bedini A, Rivara S, Mor M. Melatonin receptor agonists: new options for insomnia and depression treatment. CNS Neurosci Ther. 2011;17(6):733-741. doi:10.1111/j.1755-5949.2010.00197.x

18. de Bodinat C, Guardiola-Lemaitre B, Mocaer E, Renard P, Munoz C, Millan MJ. Agomelatine, the first melatonergic antidepressant: discovery, characterization and development. Nat Rev Drug Discov. 2010;9(8):628-642. doi:10.1038/nrd3140

19. Kennedy SH, Rizvi SJ. Agomelatine in the treatment of major depressive disorder: potential for clinical effectiveness. CNS Drugs. 2010;24(6):479-499. doi:10.2165/11534420-000000000-00000

20. Williams WP, McLin DE, Dressman MA, Neubauer DN. Comparative review of approved melatonin agonists for the treatment of circadian rhythm sleep-wake disorders. Pharmacotherapy. 2016;36 (9):1028-1041. doi:10.1002/phar.1822

21. Pandi-Perumal SR, Srinivasan V, Spence DW, et al. Ramelteon: a review of its therapeutic potential in sleep disorders. Adv Ther. 2009;26(6):613-626. doi:10.1007/s12325-009-0041-6

22. Ho Chan W. Taiwan's healthcare report 2010. EPMA J. 2010;1 (4):563-585. doi:10.1007/s13167-010-0056-8

23. Chinese Hospital Association. ICD-9-CM English-Chinese Dictionary. Taipei, Taiwan: Chinese Hospital Association Press; 2000.

24. Hsieh CY, Su CC, Shao SC, et al. Taiwan's national health insurance research database: past and future. Clin Epidemiol. 2019;11:349-358. doi:10.2147/CLEP.S196293

25. Chen $\mathrm{KC}$, Chung $\mathrm{CH}, \mathrm{Lu} \mathrm{CH}$, et al. Association between the use of dipeptidyl peptidase 4 inhibitors and the risk of dementia among patients with type 2 diabetes in Taiwan. J Clin Med. 2020;9(3):660. doi: $10.3390 / \mathrm{jcm} 9030660$

26. Chen TY, Huang $\mathrm{CH}$, Chung $\mathrm{CH}$, et al. Sex and age differences in the association between anxiety disorders and narcolepsy: a nationwide population-based case control study. J Affect Disord. 2020;264:130-137. doi:10.1016/j.jad.2019.12.010

27. Lin $\mathrm{CH}$, Chien WC, Chung $\mathrm{CH}$, et al. Increased risk of dementia in patients with genital warts: a nationwide cohort study in Taiwan. J Dermatol. 2020;47(5):503-511. doi:10.1111/1346-8138.15277

28. Lin YC, Chen TY, Chien WC, et al. Stimulants associated with reduced risk of hospitalization for motor vehicle accident injury in patients with obstructive sleep apnea-a nationwide cohort study. $B M C$ Pulm Med. 2020;20(1):28. doi:10.1186/s12890-019-1041-1

29. Liu YP, Chien WC, Chung CH, Chang HA, Kao YC, Tzeng NS. Are anticholinergic medications associated with increased risk of dementia and behavioral and psychological symptoms of dementia? A nationwide 15-year follow-up cohort study in Taiwan. Front Pharmacol. 2020;11:30. doi:10.3389/fphar.2020.00030

30. Wan FJ, Chien WC, Chung CH, Yang YJ, Tzeng NS. Association between traumatic spinal cord injury and affective and other psychiatric disorders - a nationwide cohort study and effects of rehabilitation therapies. J Affect Disord. 2020;265:381-388. doi:10.1016/j.jad. 2020.01 .063
31. Wang DS, Chung CH, Chang HA, et al. Association between child abuse exposure and the risk of psychiatric disorders: a nationwide cohort study in Taiwan. Child Abuse Negl. 2020;101:104362. doi:10.1016/j.chiabu.2020.104362

32. Yang $\mathrm{CC}$, Chien WC, Chung $\mathrm{CH}$, et al. No association between human immunodeficiency virus infections and dementia: a nationwide cohort study in Taiwan. Neuropsychiatr Dis Treat. 2019;15:3155-3166. doi:10.2147/NDT.S225584

33. Ministry of Justice. National health insurance reimbursement regulations; 2014. Available from: https:/law.moj.gov.tw/LawClass/ LawAll.aspx?pcode=L0060035. Accessed May 14, 2020.

34. Ministry of Health and Welfare. The medical technology for valdoxan $^{\circledR} 25 \mathrm{mg} ; 2012$. Available from: https:/www.nhi.gov.tw/ Resource/webdata/19976_1_100BTD08005_Valdoxan\%E8\%A9\% 95\%E4\%BC\%B0\%E5\%A0\%B1\%E5\%91\%8AC_1000928.pdf. Accessed June 24, 2020.

35. Willison HJ, Jacobs BC, van Doorn PA. Guillain-Barre syndrome: surveillance and cost of treatment strategies - authors' reply. Lancet. 2017;389(10066):253-254. doi:10.1016/S0140-6736(17)30055-7

36. Group SG-BST. Randomised trial of plasma exchange, intravenous immunoglobulin, and combined treatments in Guillain-Barre syndrome. Plasma exchange. Lancet. 1997;349(9047):225-230. doi:10. 1016/S0140-6736(96)09095-2

37. Wong AHY, Umapathi T, Shahrizaila N, et al. The value of comparing mortality of Guillain-Barré syndrome across different regions. J Neurol Sci. 2014;344(1-2):60-62. doi:10.1016/j.jns.2014.06.021

38. Srinivasan V, Spence DW, Pandi-Perumal SR, Trakht I, Cardinali DP. Jet lag: therapeutic use of melatonin and possible application of melatonin analogs. Travel Med Infect Dis. 2008;6(1-2):17-28. doi:10.1016/j.tmaid.2007.12.002

39. Kennedy SH, Emsley R. Placebo-controlled trial of agomelatine in the treatment of major depressive disorder. Eur Neuropsychopharmacol. 2006;16(2):93-100. doi:10.1016/j.euroneuro.2005.09.002

40. Wichniak A, Wierzbicka A, Jernajczyk W. Sleep and antidepressant treatment. Curr Pharm Des. 2012;18(36):5802-5817. doi:10.2174/ 138161212803523608

41. Alberti S, Chiesa A, Andrisano C, Serretti A. Insomnia and somnolence associated with second-generation antidepressants during the treatment of major depression: a meta-analysis. J Clin Psychopharmacol. 2015;35 (3):296-303. doi:10.1097/JCP.0000000000000329

42. Grosshans M, Mutschler J, Luderer M, Mann K, Kiefer F. Agomelatine is effective in reducing insomnia in abstinent alcohol-dependent patients. Clin Neuropharmacol. 2014;37(1):6-8. doi:10.1097/WNF.0000000000 000007

43. Mysliwiec V, McGraw L, Pierce R, Smith P, Trapp B, Roth BJ. Sleep disorders and associated medical comorbidities in active duty military personnel. Sleep. 2013;36(2):167-174. doi:10.5665/sleep.2364

44. Maung S, Sara AE, Cohen D, Chapman C, Saggi S, Cukor D. Sleep disturbance and depressive affect in patients treated with haemodialysis. $J$ Ren Care. 2017;43(1):60-66. doi:10.1111/jorc. 12188

45. Ho A, Raja B, Waldhorn R, Baez V, Mohammed I. New onset of insomnia in hospitalized patients in general medical wards: incidence, causes, and resolution rate. J Community Hosp Intern Med Perspect. 2017;7(5):309-313. doi:10.1080/20009666.2017.1374108

46. Flaherty JH. Insomnia among hospitalized older persons. Clin Geriatr Med. 2008;24(1):51-67, vi. doi:10.1016/j.cger.2007.08.012

47. Gill D, Hatcher S. Antidepressants for depression in people with physical illness. Cochrane Database Syst Rev. 2000;(2):Cd001312.

48. Rayner L, Price A, Evans A, Valsraj K, Higginson IJ, Hotopf M. Antidepressants for depression in physically ill people. Cochrane Database Syst Rev. 2010;(3):Cd007503.

49. Zheng W, Luo XN, Li HY, et al. Regional differences in the risk of insomnia symptoms among patients from general hospital outpatient clinics. Neuropsychiatr Dis Treat. 2018;14:3307-3315. doi:10.2147/ NDT.S184216 
50. Xiang YT, Ma X, Cai ZJ, et al. The prevalence of insomnia, its sociodemographic and clinical correlates, and treatment in rural and urban regions of Beijing, China: a general population-based survey. Sleep. 2008;31(12):1655-1662. doi:10.1093/sleep/31.12.1655

51. Chang Y, Lam C, Chen SR, Sithole T, Chung MH. Seasonal variations in sleep disorders of nurses. J Clin Nurs. 2017;26(7-8):1085-1094. doi:10.1111/jocn.13519

52. Ng QX, Soh AYS, Lim DY, Yeo WS. Agomelatine, a novel therapeutic option for the management of irritable bowel syndrome. J Clin Pharm Ther. 2018;43(5):752-756. doi:10.1111/jcpt.12749

53. Vimala PV, Bhutada PS, Patel FR. Therapeutic potential of agomelatine in epilepsy and epileptic complications. Med Hypotheses. 2014;82(1):105-110. doi:10.1016/j.mehy.2013.11.017

54. Freiesleben SD, Furczyk K. A systematic review of agomelatine-induced liver injury. J Mol Psychiatr. 2015;3(1):4. doi:10.1186/s40303-015-0011-7

55. Guaiana G, Gupta S, Chiodo D, Davies SJ, Haederle K, Koesters M. Agomelatine versus other antidepressive agents for major depression. Cochrane Database Syst Rev. 2013;(12):Cd008851.

56. Chou IC, Lin HC, Lin CC, Sung FC, Kao CH. Tourette syndrome and risk of depression: a population-based cohort study in Taiwan. J Dev Behav Pediatr. 2013;34(3):181-185. doi:10.1097/DBP.0b013e3182829f2b

57. Cheng CL, Chien HC, Lee CH, Lin SJ, Yang YH. Validity of in-hospital mortality data among patients with acute myocardial infarction or stroke in National Health Insurance Research Database in Taiwan. Int J Cardiol. 2015;201:96-101. doi:10.1016/j.ijcard.2015.07.075

58. Cheng C-L, Kao Y-HY, Lin S-J, Lee C-H, Lai ML. Validation of the National Health Insurance Research Database with ischemic stroke cases in Taiwan. Pharmacoepidemiol Drug Saf. 2011;20(3):236-242. doi:10.1002/pds.2087
59. Sung SF, Hsieh CY, Lin HJ, Chen YW, Yang YH, Li CY. Validation of algorithms to identify stroke risk factors in patients with acute ischemic stroke, transient ischemic attack, or intracerebral hemorrhage in an administrative claims database. Int $J$ Cardiol. 2016; 215:277-282.

60. Tseng HP, Lin FJ, Chen PT, et al. Derivation and validation of a discharge disposition predicting model after acute stroke. J Stroke Cerebrovasc Dis. 2015;24(6):1179-1186. doi:10.1016/j.jstrokecerebrovasdis.2015.01.010

61. Su VY, Liu CJ, Wang HK, et al. Sleep apnea and risk of pneumonia: a nationwide population-based study. CMAJ. 2014;186(6):415-421. doi:10.1503/cmaj.131547

62. Wu CS, Lai MS, Gau SS, Wang SC, Tsai HJ. Concordance between patient self-reports and claims data on clinical diagnoses, medication use, and health system utilization in Taiwan. PLoS One. 2014;9(12): e112257. doi:10.1371/journal.pone.0112257

63. Yu ST, Chang HY, Lin MC, Lin YH. Agreement between self-reported and health insurance claims on utilization of health care: a population study. J Clin Epidemiol. 2009;62(12):1316-1322. doi:10.1016/j.jclinepi.2009.01.016

64. Huang KL, Lu WC, Wang YY, et al. Comparison of agomelatine and selective serotonin reuptake inhibitors/serotonin-norepinephrine reuptake inhibitors in major depressive disorder: a meta-analysis of head-to-head randomized clinical trials. Aust $N Z J$ Psychiatry. 2014;48(7):663-671. doi:10.1177/0004867414525837
Neuropsychiatric Disease and Treatment

\section{Publish your work in this journal}

Neuropsychiatric Disease and Treatment is an international, peerreviewed journal of clinical therapeutics and pharmacology focusing on concise rapid reporting of clinical or pre-clinical studies on a range of neuropsychiatric and neurological disorders. This journal is indexed on PubMed Central, the 'PsycINFO' database and CAS, and

\section{Dovepress}

is the official journal of The International Neuropsychiatric Association (INA). The manuscript management system is completely online and includes a very quick and fair peer-review system, which is all easy to use. Visit http://www.dovepress.com/testimonials.php to read real quotes from published authors. 